\title{
Bending Behaviour of Recycled PET Fiber Reinforced Cement-Based Composite
}

\author{
Margareth da Silva Magalhães and Matheus Soares Viana Fernandes
}

\begin{abstract}
This paper addresses the results of an investigation on the influence of Recycled PET (R-PET) fibers as reinforcement of cementitious matrix. The mixtures were produced using Portland cement, fly ash, silica sand, superplasticizer and different volumes of R-PET fibers, i.e. $0 \%$, $1.0 \%, 1.5 \%$ and $2.0 \%$. The bending performance of the mixtures was assessed based on the four-point bending test in terms of first-cracking stress, first-cracking deflection, ultimate bending strength, ultimate midspan deflection at bending strength and toughness. The results indicated that the incorporation of R-PET fibers significantly improve the post-cracking behaviour of mortars with a major improvement in mortar toughness and deflection capacity. The maximum volume of PET fibers for a desired workability and performance of the composite was $2.0 \%$, which showed a deflection hardening behaviour. Cementitious composites with $1.0 \%$ and $1.5 \%$ fiber volume content exhibited deflection-softening behaviour, with a single cracking formation.
\end{abstract}

Index Terms-Bending behaviour, cement based composite, FRC, PET fibers.

\section{INTRODUCTION}

Nowadays, there is an increasing interest in the development of eco-friendly materials. Thus, environmental challenges due to the necessity of reducing worldwide levels of $\mathrm{CO}_{2}$ emissions, to limit the energy consumption and to use recycled materials are promoting an increasing effort to find viable alternatives to minimize pollution from the main productive processes.

The interest in plastic waste materials originates mainly from environmental reasons, due to the fact that post-consumer plastics are the most relevant wastes with a low rate of biodegradation, and in consideration of the severe environmental problems created by the scarcity of space for landfilling. Thus, the waste utilization has become an attractive alternative to disposal. In recent years, several researches are being carried out on the utilization of recycled plastic in concrete as structural and non-structural low cost lightweight aggregates [1], and reinforcing fibers for eco-friendly cementitious material in the construction industry [2]-[11].

The incorporation of waste in concrete provides additional advantages in terms of environmental and potential economic considerations. It is also well known that the addition of a relatively small quantity of short random fibers to a cementitious matrix improves the mechanical response of the resulting product, commonly known as a fiber reinforced cementitious composite (FRCC). FRCCs have the potential of exhibiting higher strength and ductility in comparison to unreinforced mortar or concrete, which fail in tension immediately after the formation of a single crack.

Several researches have reported the effects of Recycled PET fibers(R-PET) as reinforcement of cementitious matrices.

Reference [3] described methods for manufacturing reinforcing fibers from recycled PET bottles, and evaluated their beneficial effects in terms of ductility and compressive strengths of concrete specimens. In the study by [6], PET fibers with different geometries (embossed, straight, and crimped) were employed to control shrinkage cracking in cementitious composites. Reference [11] analyzed the durability of recycled PET fibers used as reinforcement in cement-based materials. Reference [4] studied compressive properties of R-PET fibers reinforced cementitious composites, and bending strength of prismatic concrete specimens reinforced with both recycled PET fibers and steel bars. R-PET fiberswere produced in laboratory and used at different volume fractions $(0.5 \%, 0.75 \%$ and $1.0 \%)$. They observed significant increases in flexural strength and ductility, and slight decreases in compressive strength and elastic modulus of composites, as compared to plain concrete. The density, workability, compressive and tensile strengths and the modulus of elasticity of the mixture added with PET fibers have been investigated by [7], [12], [13].

In most of these studies, R-PET has been utilized in the concrete mix shaped as short or long strips orcircular fibers obtained by cutting waste bottles orthogonally to their longitudinal axis [8]. The R-PET fibers have a width ranging from 0.1 to $5 \mathrm{~mm}$.

Differently from previous studies, in this work an experimental program was conducted to evaluate the utilization of plastic fibers obtained from recycled polyethylene tere phthalate (PET) bottles as an eco-efficient mortar component. The R-PET fiber used in this study is produced by M\&G Fiber Brazil S.A with a length of $32 \mathrm{~mm}$ and a $14 \mu \mathrm{m}$ diameter. The PET filaments are extruded using recycled PET bottle flakes. The monofilaments can be manufactured either straight or crimped, with different profiles and diameters. Bending tests are used to analyze and characterize the mechanical properties of SHCC with different fiber volume contents $(1.0 \%, 1.5 \%$ and $2.0 \%)$.

\section{EXPERIMENTAL PROGRAM}

The authors are with the Department of Civil Construction and Transport, DCCT/FEN, State University of Rio de Janeiro, UERJ, Rio de Janeiro, RJ, Brazil (e-mail: margarethsm@yahoo.com.br,
msvfernandes@yahoo.com.br). msvfernandes@yahoo.com.br) 
Portland cement CPII F-32 composed with $6 \%$ of calcareous filler [14], with $32 \mathrm{MPa}$ of compressive strength at 28 days; fly ash; silica sand with a maximum diameter of $212 \mu \mathrm{m}$ and a density of $2.60 \mathrm{~g} / \mathrm{cm}^{3}$; and a super plasticizer, Glenium 51 (manufactured by MBT Brazil) based on modified poly car box ylic ether with $32.5 \%$ solid content and density 1.20 $\mathrm{g} / \mathrm{cm}^{3}$.

\begin{tabular}{|c|c|c|}
\hline Chemical composition (\%) & Portland Cement & Fly Ash \\
\hline $\mathrm{Na}_{2} \mathrm{O}$ & 0.331 & 0.26 \\
\hline $\mathrm{MgO}$ & 1.344 & 0.50 \\
\hline $\mathrm{Al}_{2} \mathrm{O}_{3}$ & 3.706 & 28.24 \\
\hline $\mathrm{SiO}_{2}$ & 15.326 & 57.78 \\
\hline $\mathrm{P}_{2} \mathrm{O}_{5}$ & 0.101 & 0.06 \\
\hline $\mathrm{SO}_{3}$ & 3.327 & - \\
\hline $\mathrm{Cl}$ & 0.086 & - \\
\hline $\mathrm{K}_{2} \mathrm{O}$ & 0.189 & 2.54 \\
\hline $\mathrm{CaO}$ & 71.476 & 1.26 \\
\hline $\mathrm{MnO}$ & 0.045 & 0.03 \\
\hline $\mathrm{Fe}_{2} \mathrm{O}_{3}$ & 3.777 & 4.76 \\
\hline $\mathrm{ZnO}$ & 0.034 & - \\
\hline $\mathrm{SrO}$ & 0.257 & - \\
\hline $\mathrm{TiO}_{2}$ & - & 0.95 \\
\hline $\mathrm{BaO}$ & - & $<0.16$ \\
\hline Loss on ignition $(\%)$ & 4,93 & 3,55 \\
\hline Density $\left(\mathrm{g} / \mathrm{cm}^{3}\right)$ & 3.08 & 2.35 \\
\hline
\end{tabular}

The physical and chemical properties of Portland cement and fly ash are shown in Table I and the particle size distribution of aggregate and cementitious materials can be seen in Fig. 1.The recycled PET fiber usedin this study is produced by M\&G Fiber Brazil S.A with a length of $32 \mathrm{~mm}$, a $14 \mu \mathrm{m}$ diameter, and density of $1.43 \mathrm{~g} / \mathrm{cm}^{3}$. The fibers were produced by mean of an extrusion of plastic filaments from flakes of recycled polyethylene terephthalate (R-PET).

Several unreinforced (plain) mortar and R-PET fiber reinforced composite specimens were prepared to study the influence of different volumes of the R-PET reinforcement $(1.0 \%, 1.5 \%$ and $2.0 \%)$ on the bending properties of the final material.

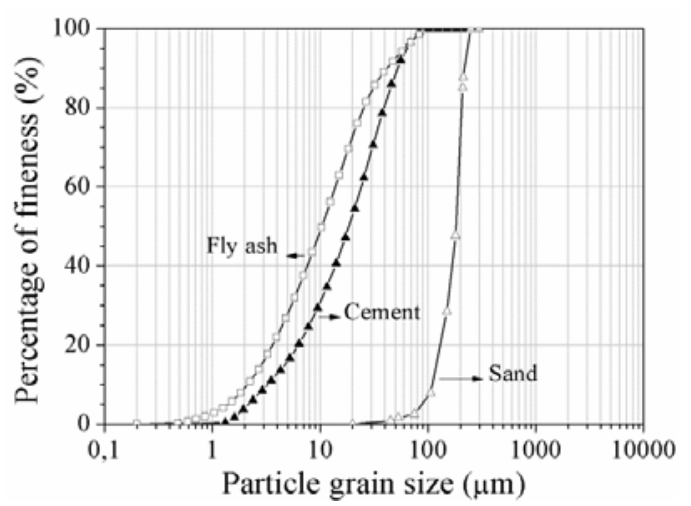

Fig. 1. Particle size distribution of cement, fly ash, fine and coarse sand.

In all composites, the water/cementitious material ratio and superplasticizer content were dosed such that all mixtures would have similar fresh properties measured by the flow table test (between 160-190 mm). A slight adjustment in the superplasticizer content in each mixture was made to achieve consistent rheological properties for better fiber distribution and workability. The mixture proportions are given in Table II.
TABLE II: MIXTURE PROPERTIES.

\begin{tabular}{lcccc}
\multicolumn{5}{c}{ TABLE II: MIXTURE PROPERTIES. } \\
\hline Ingredients & Matrix & M02 & M03 & M04 \\
\hline Fly ash $/$ cement & 1.20 & 1.20 & 1.20 & 1.20 \\
Water $/ \mathrm{MC}^{1}$ & 0.36 & 0.36 & 0.36 & 0.36 \\
Cement $\left(\mathrm{Kg} / \mathrm{m}^{3}\right)$ & 505.00 & 505.00 & 505.00 & 505.00 \\
Fly ash $\left(\mathrm{Kg} / \mathrm{m}^{3}\right)$ & 605.00 & 605.00 & 605.00 & 605.00 \\
Sand $\left(\mathrm{Kg} / \mathrm{m}^{3}\right)$ & 404.00 & 404.00 & 404.00 & 404.00 \\
Water $\left(\mathrm{Kg} / \mathrm{m}^{3}\right)$ & 404.00 & 404.00 & 404.00 & 404.00 \\
Superplasticizer $\left(\mathrm{Kg} / \mathrm{m}^{3}\right)$ & 6.05 & 6.05 & 6.81 & 6.81 \\
Fiber $\left(\mathrm{Kg} / \mathrm{m}^{3}\right)$ & - & 14.33 & 21.50 & 28.66 \\
Fiber content $(\%)$ & - & 1.00 & 1.50 & 2.00 \\
\hline \multicolumn{4}{c}{$\mathrm{CM}$ : cementitious materials (cement + fly ash) }
\end{tabular}

To produce the mixtures all dry raw materials were mixed for 3 minutes in a mechanical mixer with a 20 liter capacity. Water and superplasticizer were added to form the basic matrix. The mixture was stirred for another 8 minutes to allow adequate flowability and viscosity, both of which are necessary for good workability and uniform fiber distribution. In the last step, fibers were dispersed carefully by hand into the mortar mixture and the mixture was stirred for 5 minutes more.

A small flow cone for conventional flow table test was used to quantify the deformability of the fresh mix according to [15]. Then, the specimens were cast in steel moulds and demolded 24 hours after casting, always covered with damp cloths. The specimens were cured for 28 days in a curing chamber with $100 \%$ relative humidity and $21 \pm 1^{\circ} \mathrm{C}$ of temperature.

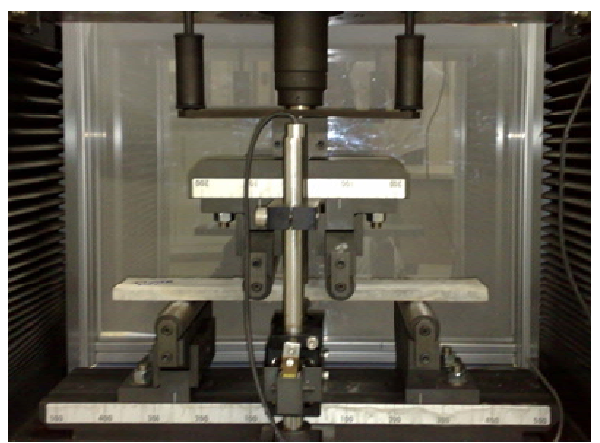

Fig. 2. Bending test set-up.

\section{B. Testing Procedure}

To determine the bending behavior of the studied composites, a Shimadzu Universal testing machine with a capacity of $100 \mathrm{kN}$ was used. The tests were carried out at a crosshead rate of $0.2 \mathrm{~mm} / \mathrm{min}$.

Three samples measuring $400 \times 60 \times 12.5 \mathrm{~mm}$ (length $\times$ width $\times$ thickness) were tested under four point bending loads at a span of $255 \mathrm{~mm}$ as seen in Fig. 2. Deflections at mid-span were measured using an electrical transducer (LVDT). The loads and corresponding deflections were continuously recorded on a computerized data recording system.

\section{RESULTS AND DISCUSSION}

\section{A. Bending Properties of the Composites}

The bending performance of the mixtures was assessed based on the four-point bending test in terms of first-cracking 
stress $\left(\sigma_{c r}\right)$, first-cracking deflection $\left(\delta_{c r}\right)$, ultimate bending strength $\left(\sigma_{u}\right)$, ultimate midspan deflection at bending strength $\left(\delta_{u}\right)$, which will be referred to as deflection capacity, and toughness. In this research, the toughness was computed as

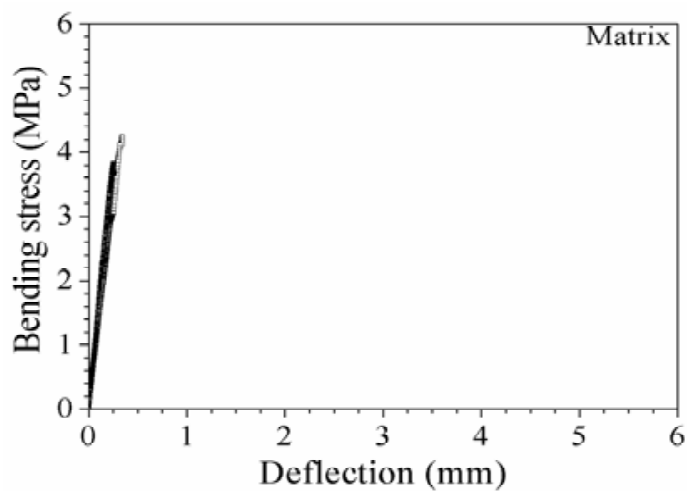

(a)

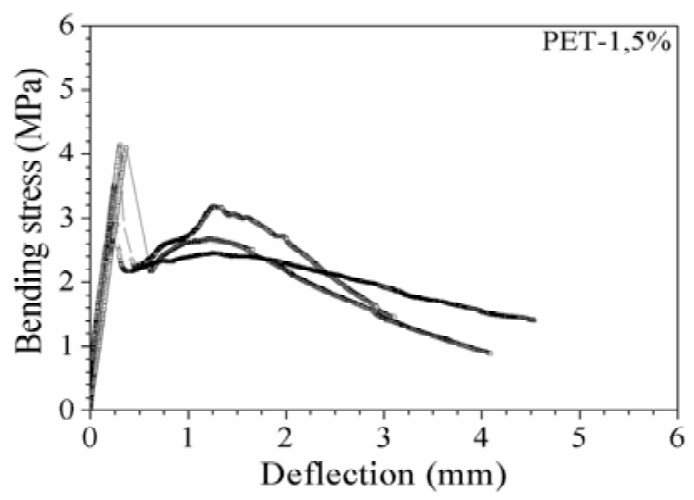

(c) the total area under the bending stress - deflection curve while the first cracking point is defined as the point where nonlinearity in the bending stress-deflection curve becomes evident.

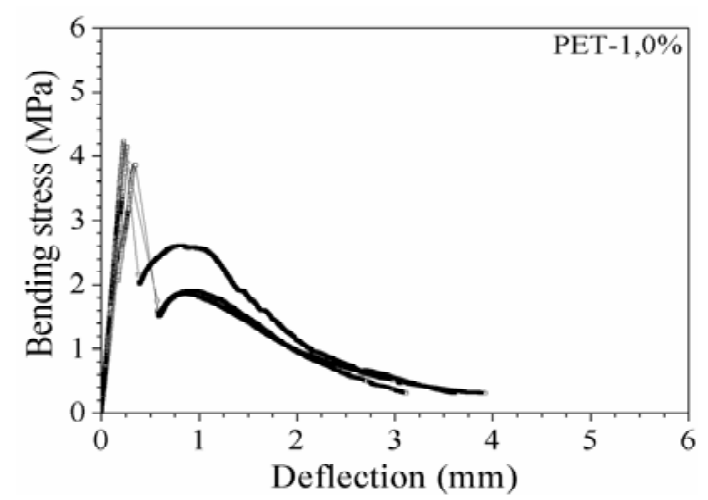

(b)

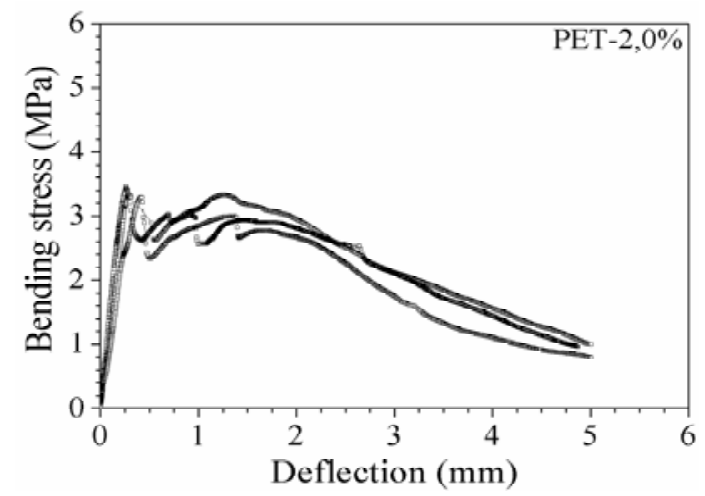

(d)

Fig. 3. Equivalent bending stress-strain curves of the composites at 28 days. (a) Unreinforcedcomposite and composites reinforced with (b) $1.0 \%$, (c) $1.5 \%$ and (d) $2.0 \%$.

Equivalente bending stress - deflection curves obtained for experimental mixtures are shown in Fig. 3. The results of the evaluation of all curves are summarized in Table III. Each result in Table III is the average of three specimens.

Fig. 3a shows the curves from the bending tests on mortar mixture without reinforcement, where the maximum stress is at an average deflection of $0.304 \mathrm{~mm}$ (deflection at the maximum load point); following this, the load suddenly decreases. However, when the content of R- PET fibre increase from 1.0 to $2.0 \%$ (Fig. $3 \mathrm{~b}-\mathrm{d}$ ), the bending behaviour is supposed to increase owing to the fact that a greater amount of fibre exists, which enables a greater capability of resisting the tensile stress, especially at the post-cracking stages.

Comparing the results fromTable III, it can be noticed that as the fiber volume content increases, the first cracking strength decreases from 4.06 $\mathrm{MPa}$ (Matrix) to $3.27 \mathrm{MPa}$ (M04-2\%fiber), in accordance with what was expected as the introduction of the fibers damage the matrix [16]. However, the tests results have shown no differences infirst-cracking deflection when the fiber volume content increases from 1.0 to $2.0 \%$.

Concerning the post-cracking behaviour, Fig. 3b-d indicated that, even though the test series demonstrated a range of performance, both test series with $1.0 \%$ and $1.5 \%$ fiber volume content (Fig. 3b-c) exhibited deflection-softening behaviour, with a single cracking formation, while the test with $2.0 \%$ fiber volume content (Fig. 3d), generated a performance in the edge of the deflection-hardening behaviour (maximum post-cracking bending stress is similar or higher than first-cracking strength), with a single cracking formation surrounded by ramifications. According to [17], fiber reinforced cementitious composite showing deflection-hardening behavior generates a higher load carrying capacity after first cracking compared with normal concrete or composite with deflection-softening behaviour.

Comparing the effect of fiber volume fraction on pos-cracking value, it is evident the beneficial influence of the fiber in pos-cracking behaviour of fiber reinforced cementitious composites. The results indicated that when the contents of R-PET fibre increased from 1.0 to $1.5 \%$, the ultimate bending strengthincreased from 2.58 to $2.84 \mathrm{MPa}$ and deflection capacityincreased from 0.94 to $1.32 \mathrm{~mm}$ and when the content of R-PET fibre increased to $2.0 \%$, the ultimate bending strength increased from 2.58 to $3.03 \mathrm{MPa}$ and deflection capacity increased from 0.94 to $1.43 \mathrm{~mm}$. This represents an increase of up to 4.7 times in comparison to the deflection capacity of unreinforced matrix.

There is need for high energy absorbing materials that will mitigate the hazards for structures subjected to dynamic loads, such as seismic, impact and blast. Thus comparing energy absorption capacity provides useful information for such applications. The effect of fiber volume content on energy absorption capacity is illustrated in Fig. 4 by using toughness 
values, defined as the the total area under the bending stress deflection curve.

As shown in Fig. 4, there is noticeable differences between specimens with different fiber volume contents. For example, samples reinforced with $1 \%$ R-PET fibers showed toughness value of approximately $4.60 \mathrm{~J} / \mathrm{m}^{3}$, while samples reinforced with $1.5 \%$ and $2.0 \%$ of R-PET fibers showed $7.2 \mathrm{~J} / \mathrm{m}^{3}$ and 8.2 $\mathrm{J} / \mathrm{m}^{3}$, respectively. This indicates an increase of up to $76 \%$ on absorption capacity of composite reinforced with $2.0 \%$ of R-PET fiber.

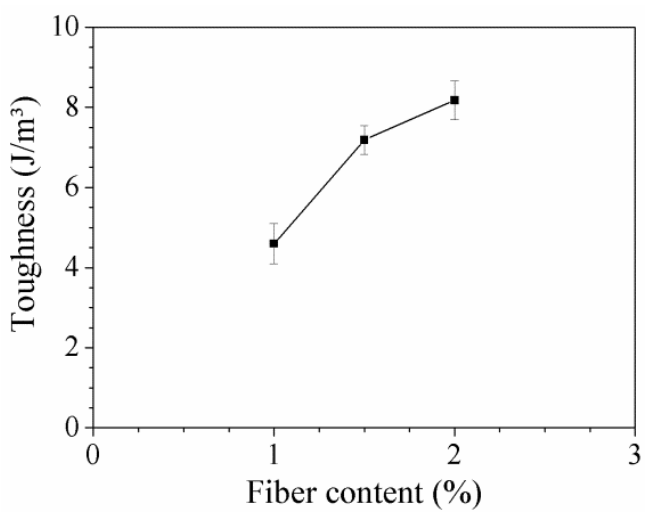

Fig. 4. Effect of fiber volume content on toughness.

TABLE III: SUMMARY OF BENDING TESTS OF MIXTURES AT 28 DAYS (MEAN VAlUes AND STANDARD DEVIATION IN PARENTHESIS)

\begin{tabular}{ccccc}
\hline Mix & $\delta_{c r},(\mathrm{~mm})$ & $\sigma_{c r}(\mathrm{MPa})$ & $\sigma_{u}(\mathrm{MPa})$ & $\delta_{u}{ }^{1}(\mathrm{~mm})$ \\
\hline Matrix & $0.304(0,047)$ & $4.06(0.21)$ & - & - \\
M02 & $0.277(0.057)$ & $4.09(0.19)$ & $2.58(0.57)$ & $0.94(0.04)$ \\
M03 & $0.276(0.041)$ & $4.00(0.72)$ & $2.84(0.54)$ & $1.32(0.03)$ \\
M04 & $0.275(0.018)$ & $3.27(0.22)$ & $3.03(0.29)$ & $1.43(0.14)$ \\
\hline \multicolumn{5}{l}{ The ultimate deflection refers to the deflection when crack opening }
\end{tabular}
localization occurs

\section{CONCLUSIONS}

Based on the results obtained in the present work it can be concluded that the use of Recycled PET (R-PET) fibers, as reinforcement of cement composites, is a promising technique for developing sustainable materials to be applied in the civil construction industry.

Cementitious composites reinforced with $1.0 \%$ and $1.5 \%$ fiber volume content exhibited deflection-softening behaviour, with a single cracking formation, while the mixture reinforced with $2.0 \%$ R-PET fibers presented a deflection-hardening behaviour with an averageultimate bending strength of $3.03 \mathrm{MPa}$, ultimate deflection at bending strengthabout of $1.43 \mathrm{~mm}$ and toughness of $8.18 \mathrm{~J} / \mathrm{m}^{3}$. In fact, the use of R-PET fibers as reinforcement of cement mortar can produce composites with appropriate mechanical properties allowing its use in semi-structural applications. In further works, the matrix might be optimized in order to obtained composites with improved bending performance

\section{ACKNOWLEDGMENT}

The authors acknowledge the Brazilian Agency FAPERJ for the financial support.

\section{REFERENCES}

[1] M. Frigione. "Recycling of PET bottles as fine aggregate in concrete," Waste Manage, vol. 30, pp.1101-1106, 2010.
[2] F. Fraternali, V. Ciancia, R. Chechile, G. Rizzano, L. Feo, and L. Incarnato, "Experimental study of the thermo-mechanical properties of recycled PET fiber-reinforced concrete," Compos Struct, vol. 93, pp 2368-2374, 2011

[3] T. Ochi, S. Okubo, and K. Fukui, "Development of recycled PET fiber and its application as concrete-reinforcing fiber," Cem Concr Compos, vol. 29, pp. 448-455, 2007.

[4] S. B. Kim, N. H Yi, H. Y. Kim, J. Kim, and Y. Song, "Material and structural performance evaluation of recycled PET fiber reinforced concrete," Cem Concr Compos, vol. 32, pp. 232-240, 2010.

[5] F. Fraternali, I. Farina, C. Polzone, E. Pagliuca, and L. Feo, "On the use of R-PET strips for the reinforcement of cement mortars," Compos Part B: Eng, vol. 46, pp. 207-210. 2013

[6] J. J. Kim, C. G. Park, S. W. Lee, S. W. Lee, and J. P. Won, "Effects of the geometry of recycled PET fiber reinforcement on shrinkage cracking of cement-based composites," Compos Part B: Eng, vol. 39, pp. 442-450, 2008

[7] D. Foti, "Preliminary analysis of concrete reinforced with waste bottles PET fibers," Constr Build Mater, vol. 25, pp. 1906-1915, 2011.

[8] D. Foti, "Use of recycled waste pet bottles fibers for the reinforcement of concrete," Compos Struct, vol. 96, pp. 396-404, 2013

[9] L. A. P. Oliveira and J. P. C. Gomes, "Physical and mechanical behaviour of recycled PET fibre reinforced mortar," Constr Build Mater, vol. 25, pp. 1712-1717, 2011.

[10] R. Siddique, J. Khatib, and I. Kaur, "Use of recycled plastic in concrete: a review," Waste Manage, vol. 28, pp.1835-1852, 2008.

[11] D. A Silva, A. M. Betioli, P. J. P. Gleize, H. R .Roman, L. A. Gómez, and J. L. D Ribeiro, "Degradation of recycled PET fibers in Portland cement-based materials," Cem Concr Res, vol. 35, pp. 1741-1746, 2004.

[12] Y. W. Choi, D. J. Moon, J. S. Chung and S. K. Cho, "Effects of waste PET bottles aggregate on the properties of concrete," Cem Concr Res, vol.35, n. 4, pp. 776-781, 2005.

[13] O. Y. Marzouk, R. M. Dheilly, and M. Queneudec, "Valorization of post-consumer waste plastic in cementitious concrete composites," Waste Manage, vol. 27, pp. 310-318, 2007.

[14] Cimento Portland Composto, NBR 11578, Associação Brasileira de Normas Técnicas (ABNT), p. 5, 1991.

[15] Argamassa Para Assentamento e Revestimento de Paredes e Tetos Preparo da Mistura e Determinação do íNdice de Consistência, NBR 13276, Associação Brasileira de Normas Técnicas (ABNT), 3p, 2005.

[16] A. Bentur and S. Mindess, Fibre Reinforced Cementitious Composites 2nd ed. Modern Concrete Technology, vol. 15, 2007, pp. 108-120.

[17] D. J. Kim, A. E. Naaman, and S. E. Tawil, "Comparative flexural behavior of four fiber reinforced cementitious composites," Cem Concr Compos, vol. 30, pp. 917-928, 2008.

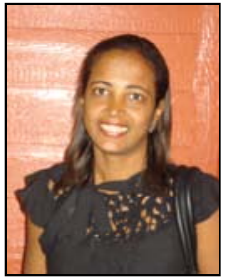

M. S. Magalhães is an assistant professor in the Department of Civil Construction and Transports, at the State University of Rio de Janeiro- UERJ, Rio de Janeiro, RJ, Brazil. She received her B.Sc. in 1996, She received her M.Sc. in 1999 and She received her Ph.D. in 2010 in civil engineering from COPPE, Federal University of Rio de Janeiro. Postdoctoral researcher at COPPE, Federal University of Rio de Janeiroin partnership with Technische Universitat Dresden / Germany from 2010 to 2011 .

She has experience in the field of civil engineering with emphasis in construction materials. Her main research interests include development of fiber reinforced cementitious composites, temperature effect on the performance of cementitious composites and development of new building materials with low environmental impact.

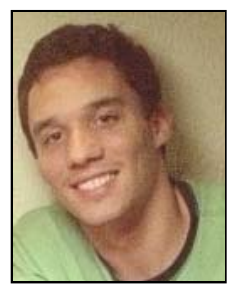

M. S. V. Fernandes is a civil engineering student in the Department of Civil Construction and Transports, State University of Rio de Janeiro - UERJ, Rio de Janeiro, RJ, and Brazil since 2012. 